\title{
The Impact of Vitamin D Level on COVID-19 Infection: Systematic Review and Meta-Analysis
}

\author{
Amare Teshome ${ }^{1}$, Aynishet Adane ${ }^{2 \star}$, Biruk Girma ${ }^{1}$ and Zeleke A. Mekonnen ${ }^{3}$ \\ ${ }^{1}$ Department of Dentistry, School of Medicine, College of Medicine, and Health Science, University of Gondar, Gondar, \\ Ethiopia, ${ }^{2}$ Department of Internal Medicine, School of Medicine, College of Medicine and Health Science, University of \\ Gondar, Gondar, Ethiopia, ${ }^{3}$ College of Medicine and Health Science, Institute of Public Health, University of Gondar, Gondar, \\ Ethiopia
}

Background: Coronavirus disease (COVID-19) is a respiratory and systemic disorder caused by Severe Acute Respiratory Syndrome Coronavirus 2 (SARS-CoV-2) or novel Coronavirus (nCoV). To date, there is no proven curative treatment for this virus; as a result, prevention remains to be the best strategy to combat coronavirus infection (COVID-19). Vitamin D deficiency (VDD) has been proposed to play a role in coronavirus infection (COVID-19). However, there is no conclusive evidence on its impact on COVID-19 infection. Therefore, the present review aimed to summarize the available evidence regarding the association between Vitamin $D$ levels and the risk of

\section{OPEN ACCESS}

Edited by:

Marc Jean Struelens,

Université Libre de Bruxelles, Belgium

Reviewed by:

Grigorios Panagiotou, Newcastle Hospitals, United Kingdom Nasser M. Al-Daghri,

King Saud University, Saudi Arabia

*Correspondence:

Aynishet Adane ayne.2003@yahoo.com

Specialty section: This article was submitted to Infectious Diseases - Surveillance,

Prevention and Treatment, a section of the journal

Frontiers in Public Health

Received: 31 October 2020

Accepted: 10 February 2021

Published: 05 March 2021

Citation:

Teshome A, Adane A, Girma B and Mekonnen ZA (2021) The Impact of

Vitamin D Level on COVID-19 Infection: Systematic Review and Meta-Analysis.

Front. Public Health 9:624559. doi: 10.3389/fpubh.2021.624559 COVID-19 infection.

Methods: A systematic literature search of databases (PUBMED/MEDLINE, Cochrane/Wiley library, Scopus, and SciELO) were conducted from May 15, 2020, to December 20, 2020. Studies that assessed the effect of vitamin D level on COVID-19/SARS-2 infection were considered for the review. The qualities of the included studies were evaluated using the JBI tools. Meta-analysis with a random-effects model was conducted and odds ratio with their $95 \% \mathrm{Cl}$ were reported. This systematic review and meta-analysis are reported according to the preferred reporting items for systematic review and meta-analysis (PRISMA) guideline.

Results: The electronic and supplementary searches for this review yielded 318 records from which, only 14 of them met the inclusion criteria. The qualitative synthesis indicated that vitamin D deficient individuals were at higher risk of COVID-19 infection as compared to vitamin $\mathrm{D}$ sufficient patients. The pooled analysis showed that individuals with Vitamin-D deficiency were $80 \%$ more likely to acquire COVID-19 infection as compared to those who have sufficient Vitamin D levels $(\mathrm{OR}=1.80 ; 95 \% \mathrm{Cl}: 1.72,1.88)$. Begg's test also revealed that there was no significant publication bias between the studies $(P=0.764)$. The subgroup analysis revealed that the risk of acquiring COVID-19 infection was relatively higher in the case-control study design $(\mathrm{OR}=1.81)$.

Conclusions: In conclusion, low serum $25(\mathrm{OH})$ Vitamin-D level was significantly associated with a higher risk of COVID-19 infection. The limited currently available data suggest that sufficient Vitamin D level in serum is associated with a significantly decreased risk of COVID-19 infection.

Keywords: vitamin D, COVID-19, SARS-CoV-2, review, meta-analysis 


\section{INTRODUCTION}

Coronavirus disease (COVID-19) is a respiratory and systemic disorder caused by Severe Acute Respiratory Syndrome Coronavirus 2 (SARS-CoV-2) or novel Coronavirus (nCoV) (1). Severe Acute Respiratory Syndrome Coronavirus 2 is one of the coronavirus families, a family that was responsible for Middle East Respiratory Syndrome (MERS) and Severe Acute Respiratory Syndrome (SARS) (2). Coronavirus disease was first reported at Wuhan City, China in December $2020(3,4)$.

World Health Organization (WHO) declared the COVID-19 outbreak to be a public health emergency on January 30, 2020 (5) and a pandemic on March 11, 2020 (6). Till the 20th of December 2020, around 75 million COVID-19 cases and 1.7 million deaths were reported worldwide (7).

To date, there is no proven curative treatment for this virus; as a result, prevention remains to be the best strategy to combat COVID-19 pandemic. One of the preventive modalities is thought to be vitamin $\mathrm{D}(1,25$-dihydroxy vitamin $\mathrm{D} 3)$ supplementation as evidenced by some observational studies. Some studies demonstrated that vitamin D deficiency (VDD) was associated with acute viral respiratory tract infection particularly caused by the influenza virus and acute lung injury $(8,9)$.

Vitamin D generally reduces the risk of microbial infection and death by modulating innate and adaptive immunity, and as a result of its antiviral and anti-inflammatory effects (10). Furthermore, vitamin D has a paramount effect on enhancing the expression of Angiotensin-converting enzyme 2(ACE-2), which is an important receptor mediating the pathogenesis of SARSCoV-2 infection (11). Vitamin D can also enhance the expression of antioxidation-related genes, modulate adaptive immunity, and improves cellular immunity (12).

One challenge in halting this pandemic is the absence of proven treatment for COVID-19. Supplementation of vitamin $\mathrm{D}$ has been found to decrease viral acute respiratory infections, especially in persons with VDD (13). Considering the mechanisms of action of vitamin $\mathrm{D}$, several studies have been conducted to evaluate the effect of vitamin D particularly in the context of the COVID-19 pandemic but continued to be an area of uncertainty and ongoing focus of attention $(14,15)$. However, the association between COVID-19 infection and VDD is still uncertain. Therefore, the present review is intended to summarize available literature regarding the impact of vitamin D level on COVID-19 infection.

\section{METHODS AND MATERIALS}

The results of this review are reported according to the Reporting Items for Systematic Reviews and Meta-Analyses (PRISMA) guideline (16), with the following research question: Is

Abbreviations: ACE, Angiotensin-Converting Enzyme; ARTI, Acute Respiratory Tract Infection; CDC, Centre for disease control and prevention; COVID19, Corona Virus Disease 2019; HR, Hazard Regression; JBI, Johanna Briggs Institute; PECO, population, exposure, control, and outcomes; PICO, population, intervention, control, and outcomes; RCT, Randomized Controlled Trial; SARS, Severe acute respiratory syndrome; VDD, Vitamin D Deficiency.
Vitamin-D deficiency associated with increased risk of COVID19 infection?

\section{Inclusion and Exclusion Criteria}

Using the PECO/PICO (population, exposure/Intervention, comparison/control, and Outcome) strategy, the studies that meet the following criteria were included in the study.

- Populations: Subjects participated in studies that assessed the impact of vitamin D level on COVID-19 infection.

- Exposure/Intervention: Vitamin D deficiency (VDD)

- Comparison: Sufficient vitamin D level

- The outcome of the study: COVID-19 infection (Positive or Negative).

\section{Exclusion Criteria}

- Studies with no accessible full-text

- Ecological studies

- Studies that did not report specific outcomes quantitatively

- Abstracts, comments, reviews, posters, and editorial reviews.

\section{Information Sources and Search Strategy}

We conducted a systematic search of databases (PubMed/Medline, Cochrane/Wiley library, Scopus, and SciELO) from May 15, 2020, to December 20, 2020, using key terms. Besides, reference lists of relevant studies were identified. The search strategy was built using a combination of keywords for the main axes of the research questions. The search strategy used terms related to (a) COVID-19/SARS-CoV-2 and (b) Vitamin D level/supplement. Search terms were pre-defined to allow a comprehensive search strategy that included text fields within records and Medical Subject Headings (MeSH terms) were used to help expand the search. We used Boolean operators (within each axis we combined keywords with the "OR" operator to expand the search and we then linked the search strategies for the two axes with the "AND" operator to narrow the search). No language restrictions were applied. When access to full-text articles was not available, authors were contacted through email.

\section{Study Selection}

Database search results were combined and duplicate studies were removed using Endnote (version 7) and manually. After duplicates removed, titles and abstract screening was done and studies that were irrelevant to the overarching research question and outcome of interest were excluded. Full-text articles that warranted further investigation were assessed using the inclusion criteria. Two reviewers independently screened information at each stage. The disagreement was resolved by the involvement of a third independent reviewer.

\section{Data Extraction}

Data extraction was done by two reviewers (AT, and ZA) using a standardized data extraction form. The following data were extracted from the included articles; characteristics of the study population, sample size, participant's status, and level of vitamin $\mathrm{D}$, and outcomes of the study. The reported odds ratio (OR) or Risk ratio (RR) and the corresponding 95\% CI or other relevant data were extracted. Any disagreement between the two 
reviewers was resolved by discussion and consensus. A third author (AA) was involved for persisted discrepancies. VDD and insufficiency was defined as a 25(OH) D level of $<20 \mathrm{ng} / \mathrm{mL}(50$ $\mathrm{nmol} / \mathrm{L})$ or as a $25(\mathrm{OH}) \mathrm{D}$ of $21-29 \mathrm{ng} / \mathrm{ml}(52.5-72.5 \mathrm{nmol} / \mathrm{L})$, respectively, and sufficient/normal if $25(\mathrm{OH}) \mathrm{D}$ level was $\geq 30 \mathrm{ng} / \mathrm{ml}$ (17).

\section{Risk of Bias Assessment}

The methodological quality of the studies was evaluated by two reviewers (AT and ZA) using JBI tools (18). The two authors' resolved disagreements in the assessment of the risk of bias by discussion and consensus, consulting a third author (BG) for any persistent disagreements. The kappa statistic was used to assess the level of agreement during the risk of bias assessment by the two authors.

\section{Study Outcomes}

The primary outcome of the study was COVID-19 infection. We compared the risk of developing COVID-19 infection among VDD and normal Vitamin D levels.

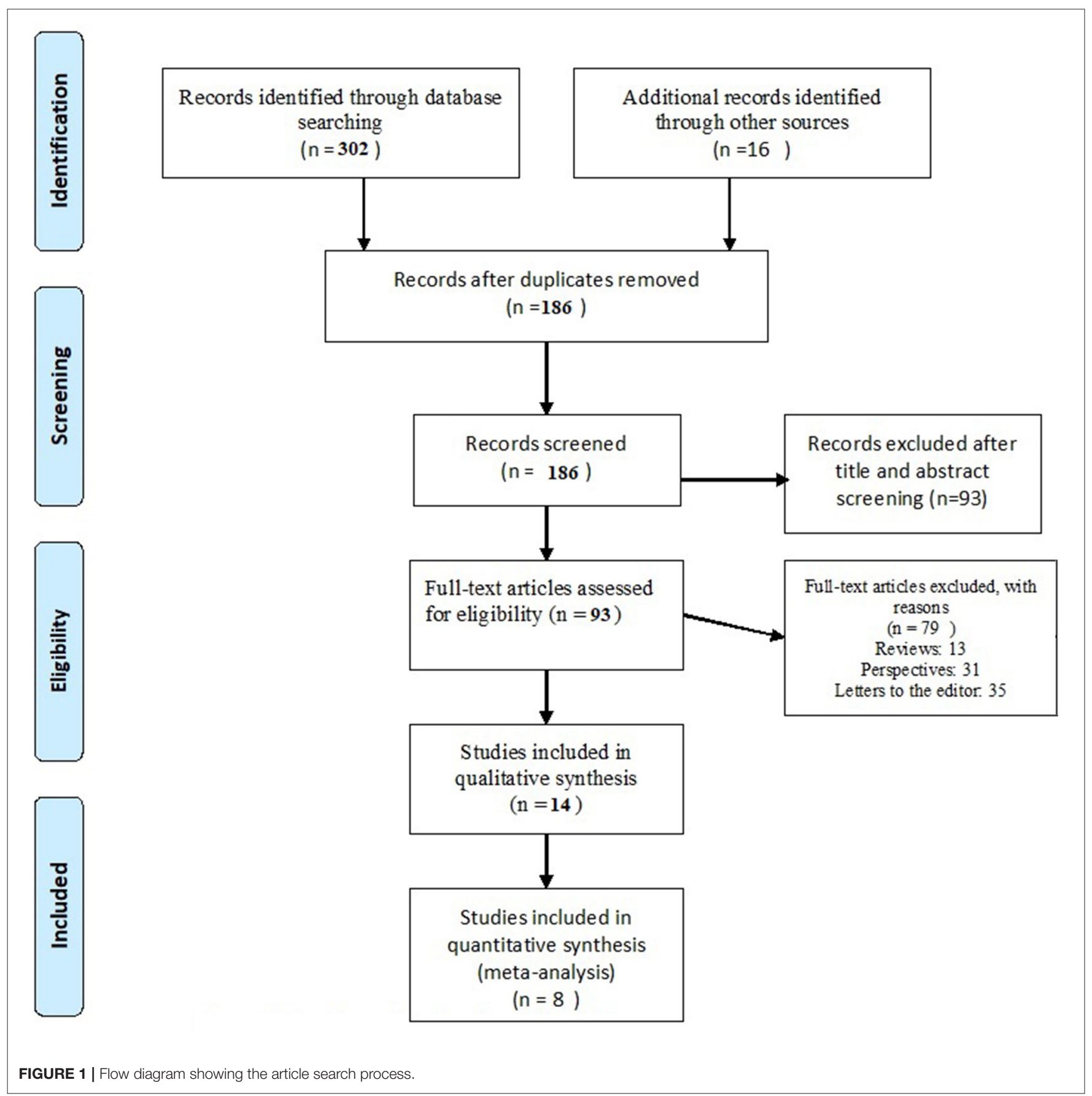


TABLE 1 | Characteristics of included studies for the systematic review and meta-analysis.

\begin{tabular}{|c|c|c|c|c|c|c|c|c|c|c|}
\hline References & Country & Sample size & $\begin{array}{l}\text { Study } \\
\text { design }\end{array}$ & Participants & Outcome & \multicolumn{5}{|c|}{ Results and conclusion } \\
\hline 1. Meltzer et al. (27) & USA & 499 & Cohort & $\begin{array}{l}\text { VDD: } 178 \\
\text { Vitamin-D sufficient: } 321\end{array}$ & $\begin{array}{l}\text { COVID-19 } \\
\text { infection }\end{array}$ & \multicolumn{5}{|c|}{$\begin{array}{l}\text { VDD }(R R=1.77) \text { are at higher risk of Covid } 19 \text { infection as compared to vitamin D } \\
\text { sufficient, with predicted COVID-19 rates in the vitamin D deficient group of } \\
21.6 \%(95 \% \mathrm{Cl}[14.0-29.2 \%]) \text { vs. } 12.2 \%(95 \% \mathrm{Cl}[8.9-15.4 \%]) \text { in the vitamin } \mathrm{D} \\
\text { sufficient group }\end{array}$} \\
\hline \multirow[t]{5}{*}{ 2. Raharusun et al. (30) } & Indonesia & 780 & Cohort & COVID_19 patients & $\begin{array}{l}\text { COVID-19 related } \\
\text { mortality }\end{array}$ & \multicolumn{5}{|c|}{$\begin{array}{l}\text { The odds of death were higher in cases with insufficient Vitamin } D \text { status }(O R=7.63 \text {; } \\
p<0.001) \text { as compared to a normal level. When compared to cases with normal } \\
\text { Vitamin } D \text { status, death was approximately } 10.12 \text { times more likely for Vitamin } D \\
\text { deficient cases }(O R=10.12 ; p<0.001)\end{array}$} \\
\hline & & & & & & \multicolumn{5}{|c|}{ Vitamin D Covid-19 case (400) Death due to CoVID-19 (380) } \\
\hline & & & & & & Normal $(=388)$ & $372(93.0 \%)$ & \multicolumn{3}{|c|}{$16(4.2 \%)$} \\
\hline & & & & & & Insufficient (213) & $26(6.5 \%)$ & \multicolumn{3}{|c|}{$187(49.1 \%)$} \\
\hline & & & & & & VDD: (179) & $2(0.5 \%)$ & \multicolumn{3}{|c|}{$177(46.7 \%)$} \\
\hline 3. Merzon et al. (22) & Israel & 7,807 & Cohort & $\begin{array}{l}\text { Covid-19 infected } \\
\text { individuals }\end{array}$ & $\begin{array}{l}\text { Vitamin D status } \\
\text { among cases and } \\
\text { Controls }\end{array}$ & \multicolumn{5}{|c|}{$\begin{array}{l}\text { Mean vitamin D level was significantly lower in COVID-19 patients than controls } \\
\text { [19.00 ng/mL ( } 95 \% \mathrm{Cl}: 18.41-19.59) \text { vs. } 20.55 \text { ( } 95 \% \mathrm{Cl} 20.32-20.78)] \text {. Low plasma } \\
25(\mathrm{OH}) \text { D level appears to be an independent risk factor for COVID-19 infection and } \\
\text { hospitalization }\end{array}$} \\
\hline 4. Hastie et al. $(15,25)$ & England & 449 & Cohort & COVID 19 patients & $\begin{array}{l}\text { COVID-19 } \\
\text { infection }\end{array}$ & \multicolumn{5}{|c|}{$\begin{array}{l}\text { There was no a potential link between vitamin D concentrations and risk of } \\
\text { COVID-19 infection }\end{array}$} \\
\hline 5. D’Avolio et al. (14) & Switzerland & 187 & cohort & $\begin{array}{l}\text { SARS-CoV-2 } \\
\text { PCR-positive }\end{array}$ & $\begin{array}{l}\text { 25-hydroxyvitamin } \\
D(25(\mathrm{OH}) \mathrm{D}) \text { level } \\
\text { among the cases } \\
\text { and control group }\end{array}$ & \multicolumn{5}{|c|}{$\begin{array}{l}\text { Significantly lower } 25(\mathrm{OH}) \mathrm{D} \text { levels were found in COVID-19 patients (median value } \\
11.1 \mathrm{ng} / \mathrm{mL} \text { ) patients compared with control groups }(24.6 \mathrm{ng} / \mathrm{mL}) \text {. } \\
\text { Vitamin D3 supplementation would be useful in the treatment of COVID- } 19 \text { infection, } \\
\text { in preventing more severe symptomatology and/or in reducing the presence of the } \\
\text { virus in the upper respiratory tract and making the patients less infectious }\end{array}$} \\
\hline \multirow[t]{5}{*}{ 6. Abdollahi et al. (32) } & Iran & 402 & Case-control & $\begin{array}{l}\text { Covid-19 positive: } 201 \\
\text { Covid-19 Negative: } 201\end{array}$ & $\begin{array}{l}\text { Status of Vitamin } \\
\text { D among the } \\
\text { control and case } \\
\text { groups }\end{array}$ & \multicolumn{5}{|c|}{$\begin{array}{l}\text { The level of serum } 25(\mathrm{OH}) \text { vitamin } \mathrm{D} \text { was significantly lower in COVID-19 } \\
\text { positive patients }(p=0.02) \text { and the results demonstrated that there was a } \\
\text { significant relationship between the levels of serum } 25(\mathrm{OH}) \text { vitamin } D \text { and } \\
\text { the vulnerability to COVID-19 }\end{array}$} \\
\hline & & & & & & \multicolumn{3}{|c|}{ Cases } & \multicolumn{2}{|l|}{ Controls } \\
\hline & & & & & & & \multicolumn{2}{|c|}{ Insufficient 162 (80.5\%) } & \multicolumn{2}{|c|}{132 (65.67\%) } \\
\hline & & & & & & & \multicolumn{2}{|c|}{ Sufficient 39 (19.4\%) } & \multicolumn{2}{|c|}{69 (34.32\%) } \\
\hline & & & & & & \multicolumn{5}{|c|}{$\begin{array}{l}\text { Vitamin D deficiency is one of the main predisposing factors associated with } \\
\text { the vulnerability to coronavirus infection in the Iranian population }\end{array}$} \\
\hline \multirow[t]{4}{*}{ 7. Ye et al. (31) } & China & 142 & Case-control & $\begin{array}{l}\text { COVID-19 positive: } 62 \\
\text { COVID-19 negative: } 80\end{array}$ & $\begin{array}{l}\text { Status of vitamin } D \\
\text { and severity of the } \\
\text { diseases }\end{array}$ & \multicolumn{5}{|c|}{$\begin{array}{l}\text { Significantly higher rates of VDD were found in COVID-19 cases ( } 41.9 \%) \\
\text { compared to control group (11.1\%) }\end{array}$} \\
\hline & & & & & & & Cases & Control & Mild/mod & Severe \\
\hline & & & & & & Deficient & $26(42)$ & $15(19)$ & $18(36)$ & $8(80)$ \\
\hline & & & & & & Non-deficient & $36(58)$ & $65(81)$ & $32(64)$ & $2(20)$ \\
\hline
\end{tabular}




\section{TABLE 1 | Continued}

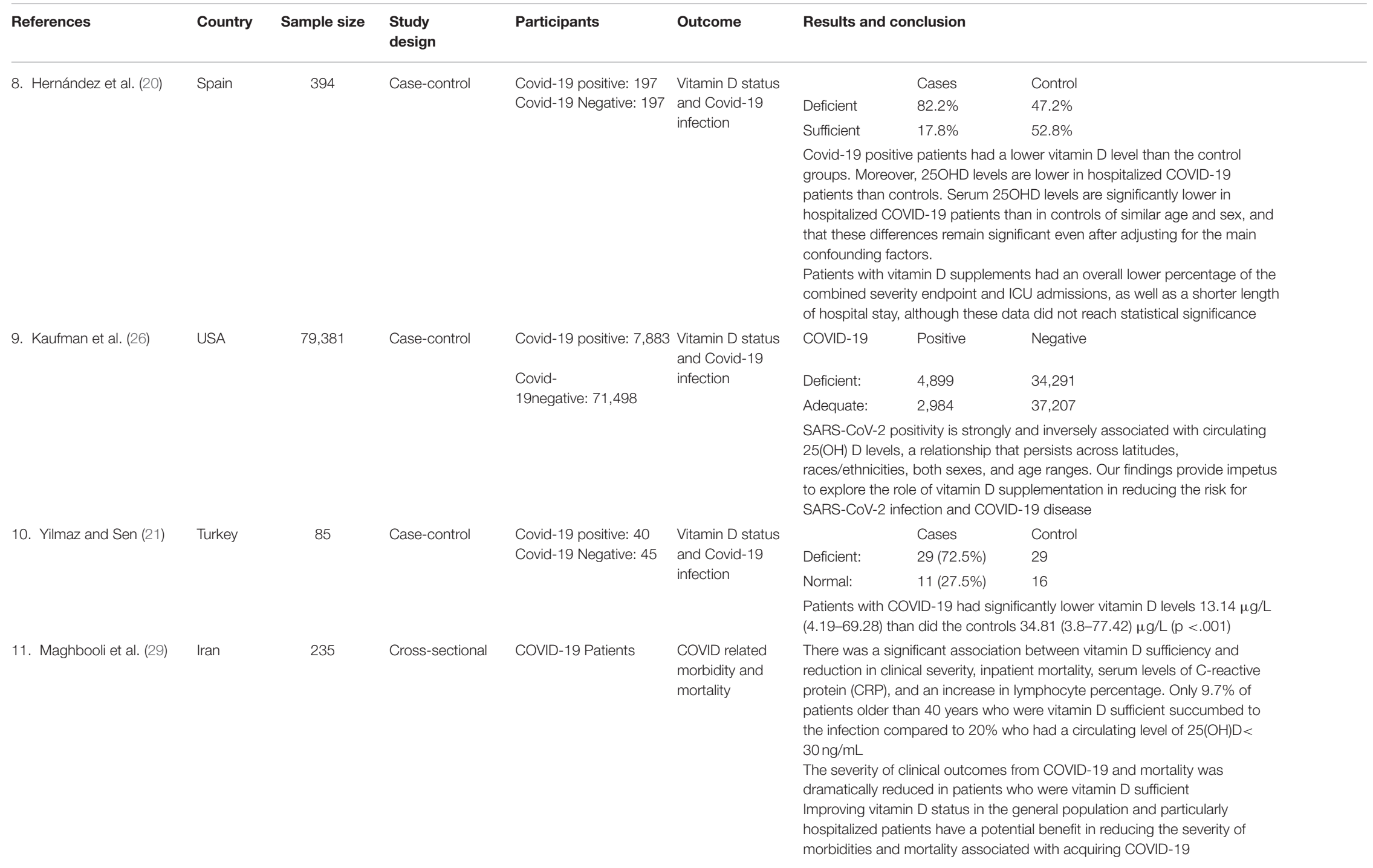




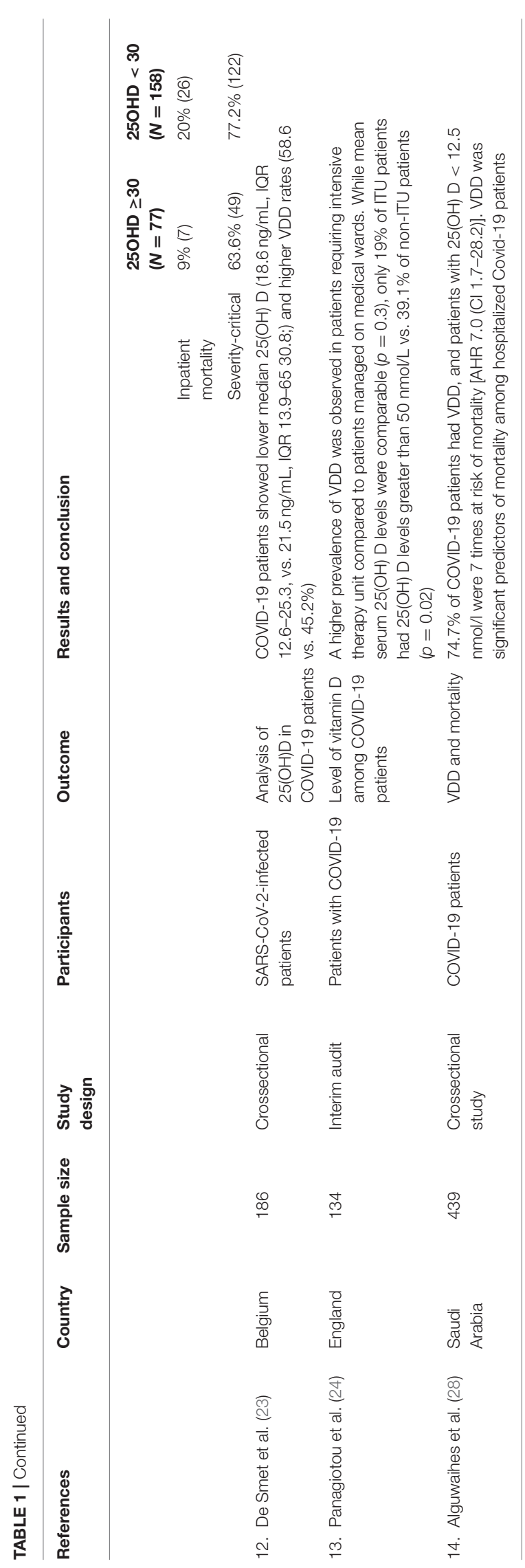

\section{Statistical Analysis}

Stata software (version 11.0, Stata Corporation, College Station, TX, US) was used to determine the pooled estimate. We used the Odds Ratio (RR) with a $95 \% \mathrm{CI}$ to estimate the impact of Vitamin D status on COVID-19 infection. The heterogeneity was evaluated using the Cochran's Q-test, deriving its magnitude from the I square $\left(I^{2}\right)(19)$, and considered to have substantial heterogeneity if the $I^{2}$ was $>50 \%$, and the random effect model is chosen; otherwise, the fixed-effect model is used. Furthermore, a sensitivity analysis was conducted by sequential removal of each study to evaluate each study's impact on the overall pooled effect. The publication bias was evaluated using Begg's tests. In all the analyses, a statistical assessment was two-tailed and considered statistically significant at a $p<0.05$.

\section{RESULTS}

\section{Study Selection}

As shown in the flow diagram (Figure 1), 318 studies were searched from all databases. Of which, 132 were excluded as duplicates using Endnote 7 software and manually. The remaining 186 studies were filtered according to the titles and abstracts; 93 studies were excluded due to unrelated themes. A full-text review was done for the remaining 93 studies and identified 14 studies that meet the inclusion criteria for this review.

\section{Study Characteristics}

Fourteen studies met the inclusion criteria with 91,120 participants. The sample size of the studies ranged from 134 to 79,381 . The studies were conducted in Europe (14, 20-25), America $(26,27)$, and Asia (28-32). Moreover, the studies were cohort studies $(14,22,25,27,30)$, case-control studies $(20,21,26$, $31,32)$, cross-sectional studies $(23,28,29)$ and interim audit $(24)$ (see Table 1).

\section{Results of Individual Studies}

Our synthesis indicated that being vitamin D deficient was at higher risk of COVID-19 infection as compared to vitamin D sufficient. This review has shown that when there is lower serum $25(\mathrm{OH}) \mathrm{D}$ level, the risk or susceptibility to COVID-19 increases $(27,29)$.

In a study conducted in England among hospitalized patients with COVID-19, VDD was associated with greater disease severity. The study indicated that a higher prevalence of Vitamin $\mathrm{D}$ deficiency (VDD) was observed in patients requiring intensive therapy unit (ITU) admission compared to patients managed on medical wards (24). A retrospective cohort study in Switzerland found significantly lower 25(OH)D levels in COVID-19 positive patients compared with negative patients (14). On contrary, findings from the UK biobank did not support the potential link between vitamin D level and risk of COVID-19 infection after adjusted for confounders (25).

A case-control study in Iran found that the level of serum $25(\mathrm{OH})$ vitamin D was significantly lower in COVID-19 positive patients $(p=0.02)$ and it demonstrated that there was a 


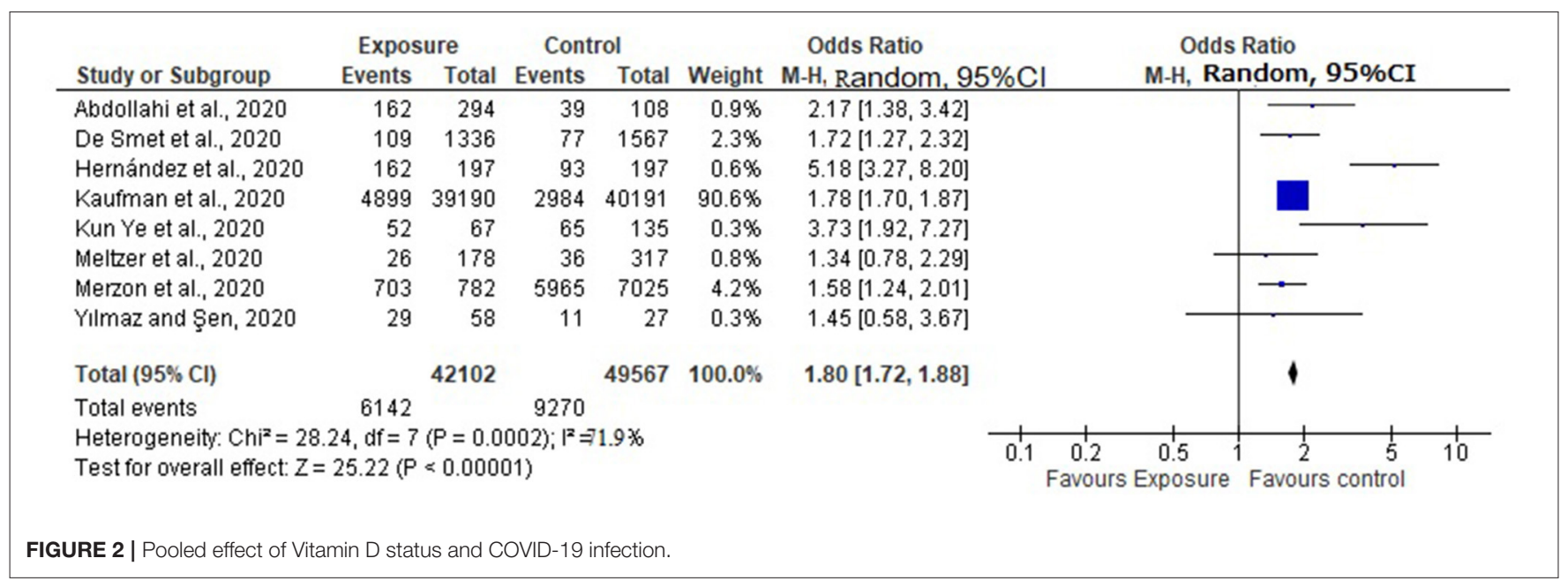

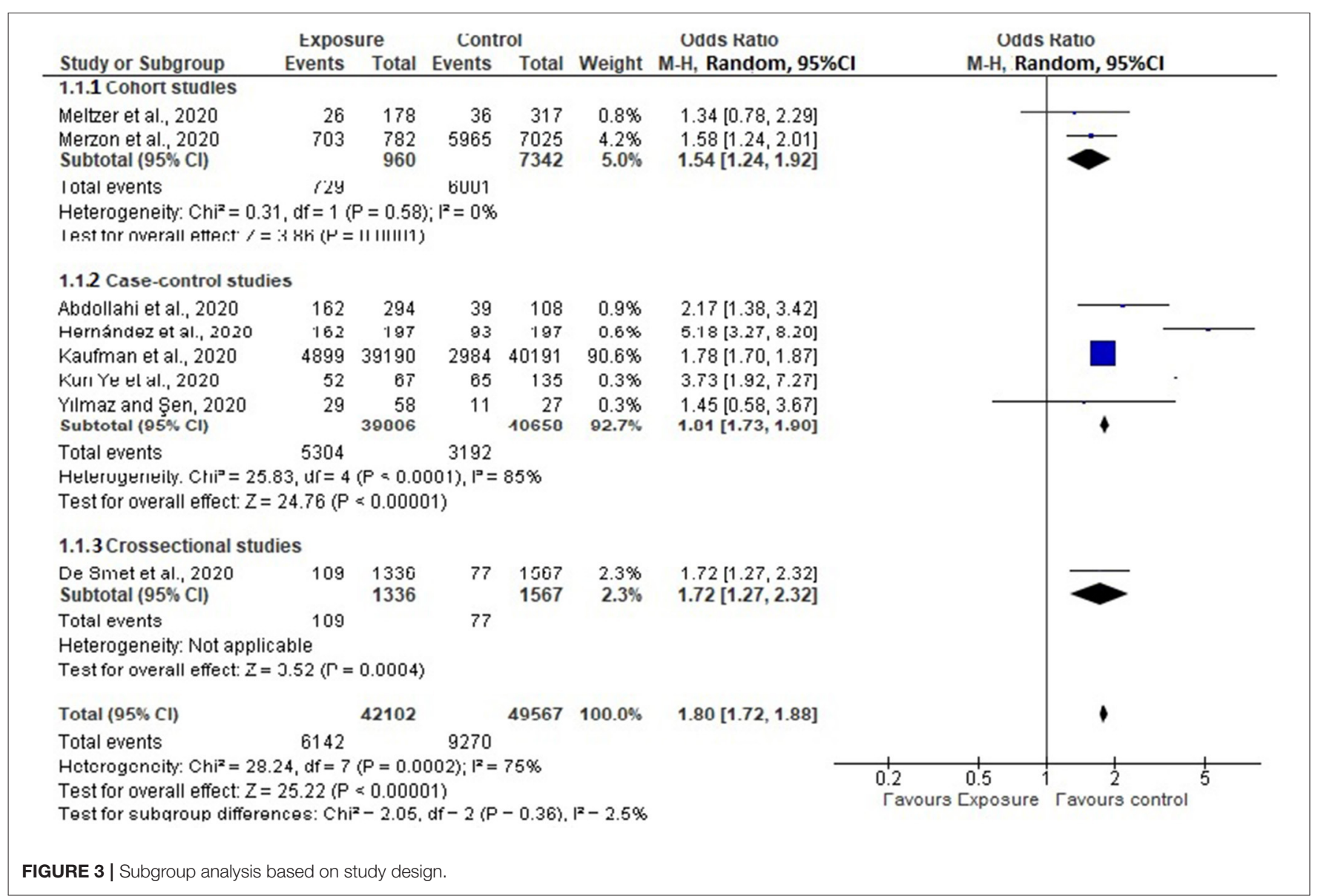

significant relationship between the levels of serum $25(\mathrm{OH})$ vitamin D and the vulnerability to COVID-19 (32). Ye et al. also revealed that VDD was a risk factor for COVID-19, especially for severe/critical cases (31). Moreover, other studies showed a lower vitamin D level in COVID-19 patients than the control group $(20,21,26)$. A study done in Saudi Arabia found that $74.7 \%$ of
COVID-19 patients had VDD and they were 7 times at risk of mortality [HR 7.0 (CI 1.7-28.2); $p=0.007$ ] (28).

A study from Belgium revealed that VDD is a prevalent risk factor for severe COVID-19 infection (23). Maghbooli et al. indicated that $25(\mathrm{OH}) \mathrm{D}$ levels of $\geq 30 \mathrm{ng} / \mathrm{mL}$ were associated with a significant decrease in the severity of clinical outcomes 
related to a COVID-19 infection (29). A population-based study from Israeli also reported that low plasma $25(\mathrm{OH}) \mathrm{D}$ level appears to be an independent risk factor for COVID-19 infection and hospitalization (22). Also, it was indicated that the odds of death were higher in COVID-19 cases with insufficient vitamin D status $(28,30)$.

A study done in Iran found that Improving vitamin D status in the general population and particularly hospitalized patients have a potential benefit in reducing the severity of morbidities and mortality associated with acquiring COVID19 (29). Moreover, D'Avolio et al. in Switzerland stated that Vitamin D3 supplementation would be useful in the treatment of COVID-19 infection, preventing more severe symptoms and/or in reducing the presence of the virus in the upper respiratory tract and making the patients less infectious (14) (Table 1).

\section{Risk of Bias Within Studies}

The qualities of the included studies were evaluated based on the JBI critical appraisal checklist and studies with a quality assessment score of 50\% and above were included in the review.

\section{Results of the Meta-Analysis}

Eight of the 14 selected studies reported the impact of vitamin D level on COVID-19 infection (20-23, 26, 27, 31, 32). Overall, pooled OR in the random-effect model showed that VDD was associated with an increased risk of COVID-19 infection $(\mathrm{OR}=1.80,95 \%$ CI: 1.72, 1.88). Accordingly, those individuals with an insufficient level of Vitamin D are $80 \%$ more likely to acquire COVID-19 infection as compared to those who have a normal level of Vitamin D. The forest plot showed substantial heterogeneity with $I^{2}$ of $79.1 \%$ (Figure 2). Begg's test revealed there was no significant publication bias between the studies $(P=0.764)$. Subgroup analysis revealed that the pooled effect of VDD was 1.81 in case-controlled studies $(\mathrm{OR}=1.81,95 \% \mathrm{CI}$ : 173, 190) (Figure 3).

\section{Sensitivity Analysis}

The sensitivity analysis revealed that the studies done by Kaufman et al. (26) and Hernandez et al. (20) were the influential studies on the overall pooled effect (Figure 4).

\section{DISCUSSION}

In the present review, we observed a significant association between a low level of Vitamin D and the risk of acquiring COVID infection, which is supported by previous studies that revealed vitamin $\mathrm{D}$ has protective effects against acute respiratory infections (13). Moreover, a meta-analysis of randomized controlled trials showed that improving vitamin D status has been associated with a reduced risk of upper or lower respiratory tract infections (13). The possible role of vitamin $\mathrm{D}$ in infectious diseases like COVID-19 is explained by its regulatory role on acquired and innate immunity (33). Evidence also indicated that vitamin D might help in the treatment of COVID-19 by preventing the cytokine storm and subsequent ARDS which is commonly the cause of mortality $(29,34)$.

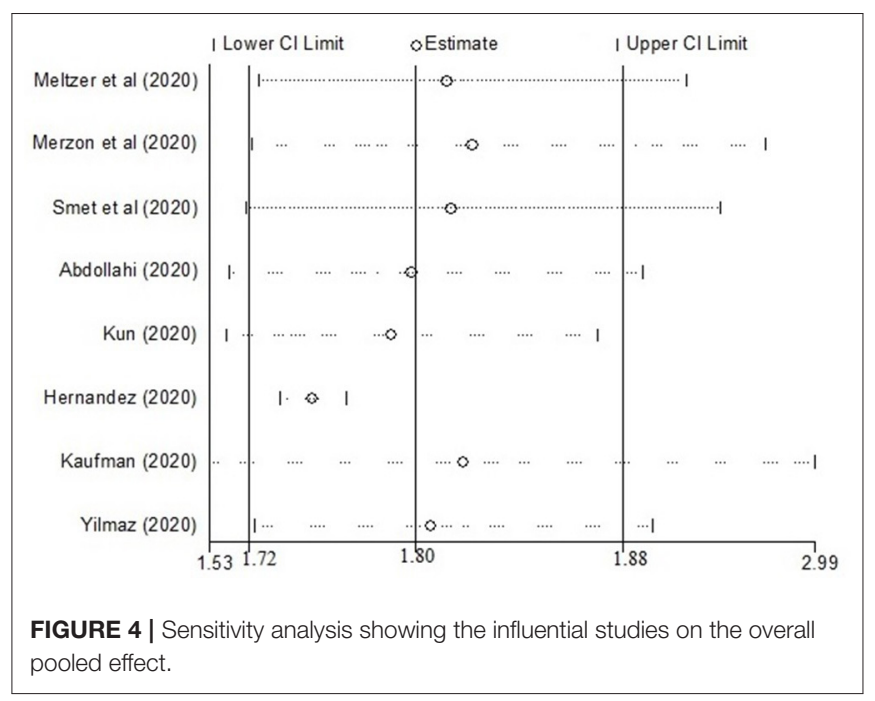

The pooled estimate showed that subjects with VDD were 80 $\%$ more likely to acquire COVID-19 infection (OR $=1.80$; $95 \%$ CI: 1.72, 1.88), which is in line with the previous meta-analysis where vitamin $\mathrm{D}$ deficiency or insufficiency participants were at increased risk of COVID-19 infection (OR $=1.43,95 \%$ CI: 1.00-2.05) (35). Besides, Ilie et al. reported that vitamin D levels are severely low in COVID-19 positive individuals and found a negative correlation between levels of mean vitamin $\mathrm{D}$ and COVID-19 infection (11).

This review showed that improving vitamin $\mathrm{D}$ status in the general population has a potential benefit in reducing the risk of acquiring COVID-19 infection. Evidence by Chandran et al. also recommends supplementation of vitamin $\mathrm{D}$ in patients with COVID-19 (36). A meta-analysis of randomized controlled trials (RCTs) concluded that the use of vitamin D supplements was associated with lower mortality in adults (37). A systematic review and meta-analysis on the effect of Vitamin D on ARTI reported that there is an inverse non-linear association between 25(OH)D concentration and risk of ARTIs (38). The evidence presented in this review showed promise for the use of Vitamin D supplementation to reduce the risk and severity of COVDI-19 infection.

\section{Limitation of the Study}

Our study has some strengths and limitations. The main strength of the current review lies in our adherence to international standardized guidelines on the conduct and reporting of systematic reviews. We included studies only from peer-reviewed journals, which may have restricted our findings. However, some of the limitations of our study include; most of the included studies were hospital-based studies and the data were from secondary sources that become more prone to high risk of bias.

\section{CONCLUSION}

In conclusion, low serum $25(\mathrm{OH})$ Vitamin-D level was significantly associated with a higher risk of COVID-19 
infection. The limited currently available data suggest that sufficient Vitamin D level in serum is associated with a significantly decreased risk of COVID-19 infection. Besides, further rigorous studies are needed to strengthen the evidence.

\section{DATA AVAILABILITY STATEMENT}

The original contributions presented in the study are included in the article/supplementary material, further inquiries can be directed to the corresponding author/s.

\section{REFERENCES}

1. Zhu N, Zhang D, Wang W, Li X, Yang B, Song J, et al. A novel coronavirus from patients with pneumonia in China. N Engl J Med. (2020). 382:72733. doi: 10.1056/NEJMoa2001017

2. de Wit E, van Doremalen N, Falzarano D, Munster VJ. SARS and MERS: recent insights into emerging coronaviruses. Nat Rev Microbiol. (2016) 14:523-34. doi: 10.1038/nrmicro.2016.81

3. Lu H, Stratton CW, Tang YW. Outbreak of pneumonia of unknown etiology in Wuhan, China: the mystery and the miracle. J Med Virol. (2020) 92:4012. doi: 10.1002/jmv.25678

4. Guo Y-R, Cao Q-D, Hong Z-S, Tan Y-Y, Chen S-D, Jin H-J, et al. The origin, transmission and clinical therapies on coronavirus disease (2019). (COVID-19) outbreak - an update on the status. Mil Med Res. (2020) 7:11. doi: 10.1186/s40779-020-00240-0

5. Sohrabi C, Alsafi Z, O'Neill N, Khan M, Kerwan A, Al-Jabir A, et al. World Health Organization declares global emergency: A review of the 2019 novel coronavirus (COVID-19). Int J Surg. (2020) 76:716. doi: 10.1016/j.ijsu.2020.02.034

6. Cucinotta M. WHO declares COVID-19a pandemic. Acta Biomed. (2020) 91:157-60. doi: 10.23750/abm.v91i1.9397

7. Worldometer. Covid-19 coronavirus pandemic. (2020)

8. Montano-loza MEAJ. Perspective: improving vitamin D status in the management of. Eur J Clin Nutr. (2020) 74:8569. doi: 10.1038/s41430-020-0661-0

9. Wei R, Christakos S. Mechanisms underlying the regulation of innate and adaptive immunity by vitamin D. Nutrients. (2015) 7:8251-60. doi: 10.3390/nu7105392

10. Hribar CA, Cobbold PH, Church FC. Potential role of vitamin d in the elderly to resist covid-19 and to slow progression of parkinson's disease. Brain Sci. (2020) 10:6-13. doi: 10.3390/brainsci10050284

11. Cristian P, Simina I, Lee S. The role of vitamin D in the prevention of coronavirus disease 2019 infection and mortality. Aging Clin Exp Res. (2020) 32:1195-8. doi: 10.1007/s40520-020-01570-8

12. Lei GS, Zhang C, Cheng BH, Lee CH. Mechanisms of action of vitamin D as supplemental therapy for Pneumocystis pneumonia. Antimicrob Agents Chemother. (2017) 61:1-13. doi: 10.1128/AAC.01226-17

13. Martineau AR, Jolliffe DA, Hooper RL, Greenberg L, Aloia JF, Bergman P, et al. Vitamin D supplementation to prevent acute respiratory tract infections: systematic review and meta-analysis of individual participant data. BMJ. (2017) 356:i6583. doi: 10.1136/bmj.i6583

14. D'Avolio A, Avataneo V, Manca A, Cusato J, De Nicolò A, Lucchini $\mathrm{R}$, et al. 25-hydroxyvitamin $\mathrm{D}$ concentrations are lower in patients with positive PCR for SARS-CoV-2. Nutrients. (2020) 12:1-7. doi: 10.3390/nu12 051359

15. Hastie CE, Mackay DF, Ho F, Celis-morales CA, Vittal S, Niedzwiedz CL, et al. Elsevier has created a COVID-19 resource centre with free information in English and Mandarin on the novel coronavirus COVID- 19. The COVID19 resource centre is hosted on Elsevier Connect, the company's public news and information (2020) 14:561-5.

\section{AUTHOR CONTRIBUTIONS}

AT, BG, and AA did the article searching. ZM and AT performed the critical appraisal and data extraction. All authors conceived and designed this review, involved in data analysis, interpretation of results, write up of the manuscript, read, and approved the manuscript.

\section{ACKNOWLEDGMENTS}

The authors thank the University of Gondar and all the authors of the original articles.

16. Moher D, Liberati A, Tetzlaff J, Altman DG, Group P. Preferred reporting items for systematic reviews and meta-analyses: the PRISMA statement. PLoS Med. (2009) 6:e1000097. doi: 10.1371/journal.pmed.1000097

17. Bolland MJ, Avenell A, Grey A. Should adults take vitamin D supplements to prevent disease? BMJ. (2016) 355:i6201. doi: 10.1136/bmj.i6201

18. Peters M, Godfrey CM, Mcinerney P, Baldini Soares C, Khalil H, Parker D. 2017 guidance for the conduct of jbi scoping reviews. Joana Briggs Inst Rev Man. (2017) 13:141-6. doi: 10.1097/XEB.0000000000000050

19. DerSimonian R, Laird N. Meta-analysis in clinical trials. Control Clin Trials. (1986) 7:177-88. doi: 10.1016/0197-2456(86)90046-2

20. Hernández JL, Nan D, Fernandez-Ayala M, García-Unzueta M, HernándezHernández MA, López-Hoyos $\mathrm{M}$, et al. Vitamin D status in hospitalized patients with SARS-CoV-2 infection. J Clin Endocrinol Metab. (2020) 20:111. doi: 10.1210/clinem/dgaa733

21. Yilmaz K, Sen V. Is vitamin D deficiency a risk factor for COVID-19 in children? Pediatr Pulmonol. (2020) 55:3595-601. doi: 10.1002/ppul.25106

22. Merzon E, Tworowski D, Gorohovski A, Vinker S, Golan Cohen A, Green I, et al. Low plasma $25(\mathrm{OH})$ vitamin $\mathrm{D}$ level is associated with increased risk of COVID-19 infection: an Israeli population-based study. FEBS J. (2020) 287:3693-702. doi: 10.1111/febs.15495

23. De Smet D, De Smet K, Herroelen P, Gryspeerdt S, Martens GA. Vitamin $\mathrm{D}$ deficiency as risk factor for severe COVID-19: a convergence of two pandemics. medRxiv. (2020) 13:1373-80. doi: 10.1101/2020.05.01.20079376

24. Panagiotou G, Tee SA, Ihsan Y, Athar W, Marchitelli G, Kelly D, et al. Low serum 25-hydroxyvitamin D $(25[\mathrm{OH}] \mathrm{D})$ levels in patients hospitalised with COVID-19 are associated with greater disease severity. Clin Endocrinol. (2020) 93:508-11. doi: 10.1111/cen.14276

25. Hastie CE, Mackay DF, Ho F, Celis-Morales CA, Katikireddi SV, Niedzwiedz CL, et al. Vitamin D concentrations and COVID-19 infection in UK Biobank. Diabetes Metab Syndr Clin Res Rev. (2020) 14:561-5. doi: 10.1016/j.dsx.2020.04.050

26. Kaufman HW, Niles JK, Kroll MH, Bi C, Holick MF. SARS-CoV-2 positivity rates associated with circulating 25-hydroxyvitamin D levels. PLoS ONE. (2020) 15:e0239252. doi: 10.1371/journal.pone.0239252

27. Meltzer DO, Best TJ, Zhang H, Vokes T, Arora V, Solway J. Association of vitamin D deficiency and treatment with COVID-19 incidence. MedRxiv Prepr Serv Health Sci. (2020) 5:1-12. doi: 10.1101/2020.05.08.20095893

28. Alguwaihes AM, Al-Sofiani ME, Megdad M, Albader SS, Alsari MH, Alelayan A, et al. Diabetes and Covid-19 among hospitalized patients in Saudi Arabia: a single-centre retrospective study. Cardiovasc Diabetol. (2020) 19:205. doi: 10.1186/s12933-020-01184-4

29. Maghbooli Z, Ebrahimi M, Shirvani A, Nasiri M, Pazoki M, Kafan S, et al. Vitamin D sufficiency reduced risk for morbidity and mortality in COVID-19 patients. PLoS ONE. (2020) 15:e0240965.

30. Raharusun P, Priambada S, Budiarti C, Agung E, Budi C. Patterns of COVID19 mortality and vitamin D: an Indonesian study. SSRN Electron J. (2020) 7:1-12. doi: 10.2139/ssrn.3585561

31. Ye K, Tang F, Liao X, Shaw BA, Deng M, Huang G, et al. Does serum vitamin level affect COVID-19 infection and its severity?-A case-control study. J Am Coll Nutr. (2020) 13:1-8. doi: 10.1080/07315724.2020.1826005 
32. Abdollahi A, Kamali Sarvestani H, Rafat Z, Ghaderkhani S, MahmoudiAliabadi M, Jafarzadeh B, et al. The association between the level of serum $25(\mathrm{OH})$ vitamin $\mathrm{D}$, obesity, and underlying diseases with the risk of developing COVID-19 infection: a case-control study of hospitalized patients in Tehran, Iran. J Med Virol. (2020) 93:1-6. doi: 10.1002/jmv.26726

33. Gruber-Bzura BM. Vitamin D and influenza-Prevention or therapy? Int J Mol Sci. (2018) 19:2419. doi: 10.3390/ijms19 082419

34. Xu Z, Shi L, Wang Y, Zhang J, Huang L, Zhang C, et al. Pathological findings of COVID-19 associated with acute respiratory distress syndrome. Lancet Respir Med. (2020) 8:420-2. doi: 10.1016/S2213-2600(20) 30076-X

35. Liu N, Sun J, Wang $X$, Zhang $T$, Zhao $M$, Li H. Low vitamin D status is associated with coronavirus disease 2019 outcomes: a systematic review and meta-analysis. Int J Infect Dis IJID Off Publ Int Soc Infect Dis. (2021) 104:58-64. doi: 10.1016/j.ijid.2020.12.077

36. Chandran M, Maung AC, Mithal A, Parameswaran R. Vitamin D in COVID - 19: dousing the fire or averting the storm? A perspective from the AsiaPacific. Osteoporos Sarcopenia. (2020) 6:97-105. doi: 10.1016/j.afos.2020. 07.003
37. Bjelakovic G, Gluud LL, Nikolova D, Whitfield K, Wetterslev J, Simonetti RG, et al. Vitamin D supplementation for prevention of mortality in adults. Cochrane Database Syst Rev. (2014) 10:CD007470. doi: 10.1002/14651858.CD007470.pub3

38. Pham H, Rahman A, Majidi A, Waterhouse M, Neale RE. Acute respiratory tract infection and 25-hydroxyvitamin D concentration: a systematic review and meta-analysis. Int J Environ Res Public Health. (2019) 16:3020. doi: 10.3390/ijerph16173020

Conflict of Interest: The authors declare that the research was conducted in the absence of any commercial or financial relationships that could be construed as a potential conflict of interest.

Copyright (c) 2021 Teshome, Adane, Girma and Mekonnen. This is an open-access article distributed under the terms of the Creative Commons Attribution License (CC $B Y)$. The use, distribution or reproduction in other forums is permitted, provided the original author(s) and the copyright owner(s) are credited and that the original publication in this journal is cited, in accordance with accepted academic practice. No use, distribution or reproduction is permitted which does not comply with these terms. 